\title{
Enrichment with Adipose-Derived Stem Cells Does Not Enhance Water-Jet Fat Graft Survival in the Breast-A Prospective Comparative Study
}

\author{
Hilkka H. Peltoniemii ${ }^{*}$, Asko Salmi ${ }^{1}$, Kai Saariniemi², Hannu Kuokkanen², Christian Herold ${ }^{3}$ \\ ${ }^{1}$ Plastic Surgery Hospital KL, Helsinki, Finland \\ ${ }^{2}$ Department of Plastic Surgery, Tampere University Hospital, Tampere, Finland \\ ${ }^{3}$ Klinik für Plastische und Ästhetische Chirurgie, Sana Klinikum Hameln-Pyrmont, Hameln, Germany \\ Email: ${ }^{\star}$ hilkka.peltoniemi@kolumbus.fi
}

How to cite this paper: Peltoniemi, H.H., Salmi, A., Saariniemi, K., Kuokkanen, H. and Herold, C. (2016) Enrichment with AdiposeDerived Stem Cells Does Not Enhance Water-Jet Fat Graft Survival in the Breast-A Prospective Comparative Study. Surgical Science, 7, 485-495.

http://dx.doi.org/10.4236/ss.2016.711065

Received: June 3, 2016

Accepted: October 24, 2016

Published: October 27, 2016

Copyright (c) 2016 by authors and Scientific Research Publishing Inc. This work is licensed under the Creative Commons Attribution International License (CC BY 4.0).

http://creativecommons.org/licenses/by/4.0/

(c) (i) Open Access

\begin{abstract}
Objective: Although research increasingly underlines the theoretical importance of adipose-derived stem cells (ASC) for successful fat transplantation, we could not prove this notion in cosmetic breast augmentation. Stem-cell-enriched breast fat transplantation did not yield better results than grafting based on the WAL (water-jet assisted liposuction) technique in terms of volume persistence. To overcome interindividual variation, intra-individual comparison was performed. Material and Methods: Four women underwent breast augmentation utilizing WAL fat transplantation with and without $e x$-vivo ASC isolation performed with the Multistation System. All patients underwent two fat transplantations for breast augmentation. In the first procedure, the left breast was augmented with stem-cell-enriched fat grafts and the right with plain WAL fat grafts. In the second surgery, the lipofilling was performed the other way round to exclude intra-individual differences in fat cell persistence. Results: MRI volumetry revealed a mean volume survival of $56 \%$ of the whole (watery) graft in the breasts with WAL only and $56 \%$ in the breasts with WAL and stem cell enrichment. While centrifugation of the WAL grafts demonstrated an average adipose content of $68 \%$, the average volume survival of the adipose tissue itself was $83 \%$ in the breasts augmented with WAL only and $83 \%$ in those with WAL with stem cell enrichment. Conclusion: Breast augmentation by means of lipofilling using WAL alone is faster and more inexpensive, carrying a lower risk of contamination and offering an equal take rate. We do not see any advantage in stem-cell-enrichment in cosmetic fat transplantation to the breast.
\end{abstract}

\section{Keywords}

Fat Transplantation, Cell-Assisted Lipotransfer, Water-Jet-Assisted Liposuction 


\section{Introduction}

Adipose tissue is rich in adipose-derived stem cells (ASCs) [1], but liposuction reduces the amount of ASCs [2]. Therefore, lipoaspirate supplementation with stromal cells and stem cells of another fat tissue aliquot has gained increasing attention [3]. The techniques described have been named cell-assisted lipotransfer (CAL) [3] or stem-cell-enriched tissue (SET) injections [4].

Kolle and colleagues analysed the survival of fat grafts with and without stem cell enrichment by means of MRI volumetry. They performed bolus injections of the fat graft into the upper arm and found a significantly better survival in the stem-cell-enrichment group where the stem cells had been expanded in laboratory conditions [5]. They concluded that the procedure of ASC-enriched fat grafting had excellent feasibility and safety. However, expansion in cell cultures yields a considerably higher stem cell count than fresh isolation in the operation theatre, and it also carries the risks associated to cell cultures. In clinical settings, fat transplantation bolus injections are strictly forbidden and may lead to catastrophic results, especially in breast surgery [6]. Therefore, the findings of Kolle et al. cannot be applied to autologous fat transplantation to the breast.

We compared the results of lipofilling with WAL (water-jet-assisted liposuction) alone and with WAL and stem cell enrichment after a technically correct injection for breast augmentation and did not find any advantage in stem cell enrichment in terms of superior fat take [7]. From various studies regarding fat graft survival, we know that there are differences in fat take between patients even when exactly the same technique is applied. In studies concerning the WAL method, $50 \%-90 \%$ of the transplanted fat graft is detectable by MRI six months after surgery, with an average volume survival of $64 \%-84 \%$ [7]-[12]. Many patients request sequential lipofilling to achieve the desired breast augmentation, and, therefore, two or more surgeries are not uncommon. To overcome confounding factors, we performed WAL both with and without stem cell enrichment by turns for each patient.

\section{Patients and Methods}

This prospective, controlled study was approved by the Ethics Committee of Tampere University Hospital (code R11014). The study was performed at a private clinic, the Plastic Surgery Hospital KL in Helsinki, Finland, which was the only hospital in Finland with the facilities for and experience in intraoperative stem cell enrichment. The study began in November 2010 and finished in October 2012.

In this prospective study, we compared WAL fat transplantation with and without stem cell enrichment intra-individually in four patients' breasts. In the WAL technique, tumescent liquid is infiltrated continuously with a moderate pressure at a low range 1 frequency (range $1-5$ ), while fat is suctioned with a low pressure (max. 0.5 bar) and rinsed automatically during the liposuction, with no centrifugation of the fat [12]. In theory, better results were expected with stem cell enrichment in comparison to standard fat grafts. 


\subsection{Patients and Surgery}

Women who requested two sequential lipofillings and agreed to participate were included in this study. The patients signed an informed consent prior to their inclusion in the study. All consultations, operations and follow-up were performed by a single surgeon (HP). The results were analysed with MRI volumetry before, between and after the procedures.

Breast malignancies were excluded in a mammogram and ultrasound before enrolment in the study. Smokers, too thin or diabetic patients as well as patients receiving oral corticosteroids were excluded from the study. The following protocol was applied: In the first procedure, the left breast was augmented with a stem-cell-enriched fat graft and the right one with a plain WAL fat graft. In the second surgery, after a minimum interval of 3.5 months, the fat enrichment was performed the other way round. This was done to avoid the development of asymmetry. In all patients, the adipose tissue was harvested applying the WAL technique. The duration of follow-up was 13.5 months [11]-[20].

\subsection{Liposuction-WAL}

Liposuction for the retrieval of fat was performed according to the WAL method, as described previously, under local anaesthesia and light sedation [12]. The body-jet system was used in combination with the LipoCollector ${ }^{\circledR}$ (human med AG, Schwerin, Germany). The tumescent solution containing $1 \mathrm{ml}$ Epinephrine 1:1000, $12.5 \mathrm{ml}$ sodiumbicarbonate and $500 \mathrm{mg}$ Lidocaine in each $1000 \mathrm{ml}$ of saline $0.9 \%$ was infiltrated 10 - 20 minutes before commencing the liposuction. A $3.8 \mathrm{~mm}$ steel cannula (yielding a particle size with a maximum diameter of $0.9 \mathrm{~mm}$ ) was used, and the suction vacuum was set to 0.5 bar. Continuous rinsing with $37^{\circ} \mathrm{C}$ tumescent solution was employed throughout the liposuction procedure for mechanical assistance and to rinse the collected fat. Centrifugation was not utilized.

\subsection{The Multistation Minilab ${ }^{\circledR}$ System and Isolation of the Stromal Fraction}

The stem cell enrichment of the graft was performed using the Multistation Minilab system (Multistation P \& C International, Korea). After harvesting with the WAL technique, the first part was used for fresh isolation of the stromal vascular fraction. The mean amount of fat used for stem cell enrichment was $134 \mathrm{ml}$ (range 110 - 150). Enzymatic digestion with collagenase (Collagenase NB6, GMP Grade, Sigma-Aldrich/Serva) was followed by cycles of rinsing and neutralisation according to the protocol. During the isolation process, the ordinary fat graft was collected, decanted in $50 \mathrm{ml}$ syringes and, after removing the visible fluid layer, mixed with the ACS-rich stroma. The mixture was gently transferred to $10 \mathrm{ml}$ syringes and injected immediately using the Celbrush $^{\mathrm{TM}}$ injector (Cytori Therapeutics Inc., San Diego, CA, USA) and a $2 \mathrm{~mm}$ blunt cannula. Via three 2-mm holes (inferolaterally, inferomedially and in the upper margin of the areola), approximately one third of the graft was injected into the pectoral mus- 
cles and retroglandular space and two thirds subcutaneously, in very thin rows to yield an as even distribution of fat graft as possible.

\subsection{Analysis of MRI by Radiologist}

All patients received three MRI scans: before the first transfer, before the second transfer (4- 8 months after the first transfer) and $4-15$ months after the second operation. Examinations were performed using a $1.5 \mathrm{~T}$ clinical whole body scanner (Philips Achieva $\mathrm{R}$ 3.2). The patient was placed in a prone position. A breast case was used to prevent compression and deformation of breast tissue. The examinations covered the entire breast in an axial scan direction. No intravascular contrast agent was used. All MRIs have been analysed by a radiologist.

\subsection{MRI Volumetry}

All volume analyses were performed by a blinded independent examiner in Germany (C.H.). Object marking was carried out using a graphic WACOM Cintiq 12WX LCD tablet $^{\circ}$ (Wacom Company Limited Kazo-shi, Saitama-ken, Japan), and segmentation and volume analysis was performed with Brainlab I plan 3.1 neuronavigation software. The selection of the region of interest and the process of MRI volumetry has been described previously [10] [13].

\section{Results}

The basic patient characteristics and all demographic data as well as the grafted and measured volumes are listed in Table 1. All four participants had two bilateral fat transfers: in patients 1 - 3 (Table 1, Figure 1), enriched fat was used in the left breast in the first operation and in the right breast in the second operation. Patients 1 and 3 had postlactational atrophy (Figure 1). Patient 2 had encapsulated $175 \mathrm{cc}$ implants (Baker IV) removed with consecutive fat grafting. Patient 4 had had a bilateral Baker IV capsular contraction of $370 \mathrm{cc}$ breast implants and a fistula on the left side. The implants, capsules and fistula had been resected seven months earlier. This patient wished to have enriching in her left breast in both transfers as her left breast was more scarred and slightly smaller than the right breast. She lost $8 \mathrm{~kg}$ after the first operation and gained $10 \mathrm{~kg}$ after the second operation, and some of the study value was thus lost.

The operation time ( 2 hours) was prolonged by approximately half an hour due to stem cell enrichment, depending on the volume of fat used for enrichment. The mean injected total volume per breast was $290 \mathrm{ml}$ (range 260 - 390), depending mainly on the breast skin area. There were no intra-or postoperative surgical complications. No oil cysts were detected in the postoperative MRI, but patient 4 with very scarred breasts had a $2 \mathrm{~cm}$ fat necrosis in the most scarred area after the first transfer with an enriched graft. After the second enriched graft in the same breast, the necrosis had disappeared, leaving a radiological finding resembling a radial scar, which was verified by core needle biopsy and a later control MRI. In all patients, the obtained volumetric change remained stable in the long term but was prone to changes in body weight. After the 
study, all patients have been followed annually by the operating surgeon either clinically or by means of email contact. Breast cancer has not occurred.

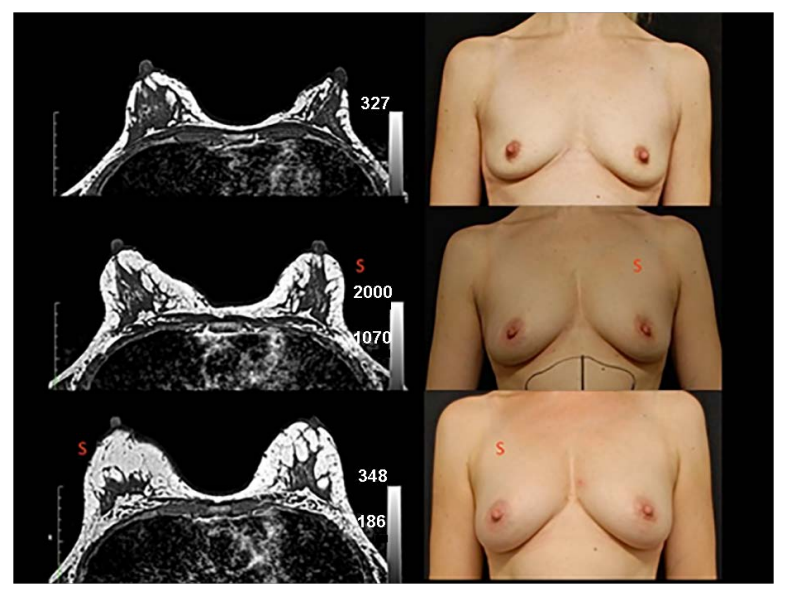

Figure 1. Patient 1 from Table 1: before surgery (top), 4 months after the first fat transfer (middle) and 6 months after the second transfer (bottom). Beside are the MRI images of the respective breasts and stem cell enrichened side marked with "S". Notice the absolutely natural appearance of the breasts and the increase in the adipose tissue layer (white) surrounding the breast glandular tissue (black).

Table 1. Demographic data on the study patients as well as the grafted volumes and fat take rates are listed in Table 1 . The volumes given in this table are pure fat contents of the fat grafts (68\% of the whole graft volume in which $32 \%$ is fluid).

\begin{tabular}{|c|c|c|c|c|c|c|c|c|c|}
\hline Patient & Operation & $\begin{array}{c}\text { Age } \\
\text { (years) }\end{array}$ & $\begin{array}{l}\text { Hormonal } \\
\text { status }\end{array}$ & BMI & $\begin{array}{l}\text { Weight change } \\
\text { postop. } \\
(\mathrm{kg})\end{array}$ & $\begin{array}{l}\text { Breast volume } \\
\text { right/left breast } \\
(\mathrm{ml})\end{array}$ & $\begin{array}{l}\text { Pure fat grafted } \\
\text { right/left breast } \\
\qquad(\mathrm{ml})\end{array}$ & $\begin{array}{c}\text { WAL } \\
\text { take (\%) }\end{array}$ & $\begin{array}{l}\text { STEM } \\
\text { take }(\%)\end{array}$ \\
\hline \multirow{2}{*}{1} & First & & & & 1 & $805 / 745$ & $184 / 184$ & 83.3 & 93.1 \\
\hline & Second & & & & 1 & $939 / 894$ & $177 / 190$ & 78.3 & 75.8 \\
\hline \multirow{2}{*}{2} & First\# & & & & 1 & $847 / 868$ & $204 / 204$ & 74 & 77.9 \\
\hline & Second & & & & 0 & $986 / 1009$ & $187 / 187$ & 75.4 & 74.3 \\
\hline \multirow[t]{2}{*}{3} & & 51 & Postmeno-pausal & 21 & & $725 / 764$ & & & \\
\hline & First & & & & 0 & $917 / 931$ & $211 / 211$ & 91.1 & 79.2 \\
\hline \multirow{3}{*}{4} & Second & & & & 10 & $1800 / 1723$ & $265 / 265$ & 81.1 & 81.5 \\
\hline & & & & & & $\mathrm{p}=0.873 \bullet^{*}$ & $\begin{array}{l}\text { MEAN patients } \\
1-3(\mathrm{SD})\end{array}$ & $82.7(8.4)$ & $82.7(9.3)$ \\
\hline & & & & & & $\mathrm{p}=0.916 \bullet^{\star}$ & $\begin{array}{c}\text { MEAN patients } \\
1-4 \text { (SD) }\end{array}$ & $79.2(11.6)$ & 79.5 (11.6) \\
\hline
\end{tabular}

BMI, body mass index; Weight change from preoperative to imaging; WAL, fat transfer with water-jet-assisted liposuction alone; STEM, fat transfer with WAL and stem cell enrichment; \# 175cc implants removed; $\bullet^{*}$ Mann-Whitney U test. 


\subsection{First Operation}

MRI volumetry revealed a mean volume survival of $56 \%$ (range $50 \%-62 \%$ ) of the whole graft in the control (WAL) breasts and 57\% (range 53\% - 63\%) in the breasts with WAL and stem cell enrichment. Patient number 4 had lost $8 \mathrm{~kg}$ (10\% of body weight) after the first operation and was therefore excluded from the group, with a volume survival of $38 \%$ and $40 \%$ in the respective breasts. While centrifugation of the watery WAL grafts demonstrated an average adipose content of $68 \%$, the mean volume survival of adipose tissue itself was $83 \%$ (range 74\% - 91\%) in the control breasts and $83 \%$ (range $78 \%-93 \%$ ) in the breasts augmented with WAL and stem cell enrichment.

\subsection{Second Operation}

MRI volumetry revealed a mean volume survival of $56 \%$ (range $51 \%-64 \%$ ) of the whole graft in the control breasts and 56\% (range 51\% - 65\%) in the breasts with WAL and stem cell enrichment. Patient number 4 had gained $10 \mathrm{~kg}$, with a volume survival of $55 \%$ and $55 \%$ in the respective breasts. The mean average volume survival of adipose tissue itself was $83 \%$ (range $75 \%$ - 94\%) in the control breasts and $82 \%$ (range $74 \%$ 96\%) in the breasts with WAL and stem cell enrichment.

The mean take rate was therefore identical for the first and second operations. The weight loss of $10 \%$ and weight gain of $14 \%$ in patient 4 had an effect on breast volume, but the effect was smaller than expected.

As it became apparent that, clinically, no benefit could be obtained from stem cell enrichment, the study was discontinued for ethical and economic reasons. All patients were satisfied or very satisfied with the results both in their breasts and in donor areas.

\section{Discussion}

The four patients constituted a very small and heterogenic group that was compensated for with the study design. Intra-individual comparison where the contralateral breast serves as a control is the best way of controlling confounding factors when comparing the two methods.

Today, MRI is the gold standard for progress control after autologous fat transplantation as it is very exact and reproducible [10] [14] and allows the control of volume survival as well as the exclusion of complications or changes within the breast tissue as the transplant recipient tissue as well [15]. Therefore, we applied MRI volumetry according to the process approved and described previously [10].

In studies showing a superior take rate and long-term fat graft survival for supplementation with ADSC, bolus injections in rodents [16] [17] or even humans [5] have been performed. As bolus injections are against the very basic principles of fat grafting [12] [18] [19], the results cannot be adopted to clinical practice as such. Yoshimura and co-workers found in their experimental studies that CAL grafts were, on average, 35\% more likely to survive than non-CAL fat grafts [20]. Based on these findings, Yoshimura reported on CAL for cosmetic breast augmentation in 40 patients in 2008 with satisfactory clinical results [3]. As a result, CAL has been adopted in both cosmetic [3] 
[21] and reconstructive [22] breast augmentation without clinical comparative studies. Our previous study was the first prospective, comparative clinical study focused on breast lipofilling with an acceptable clinical method and with reliable volumetric analysis [7]. The study compared two patient groups, and the average fat graft survival was $79 \%$ in the WAL only group (control) and $74 \%$ in the group with WAL and stem cell enrichment. The non-significant difference was probably due to the delay in the reinjection caused by the processing of the enriched lipograft. In the present study, there was no delay in the reinjection. As a result, no difference was found in fat take. As the WAL graft is rinsed and filtered automatically during liposuction, it can be transferred after a short decantation, with no processing and delay. Rinsing during harvesting eliminates most contaminants and preserves the quantity, integrity and viability of the most important components of the fat graft [23]. The fluidity of a WAL fat graft enables easy injection with a $1-2 \mathrm{~mm}$ cannula without pressure and damage to fat cells. Also, the small, consistent size of the WAL fat cell clusters $(600-900 \mu \mathrm{m})$ enables the vascularisation and survival of the whole cluster [24].

The method of enrichment, semiautomatic or manual, may not have a decisive importance for successive results. The whole concept of enrichment may be questionable in high-quality fat transfer to healthy, vital tissues. It is possible that much larger amounts of fat should be processed for stem cell isolation to reach better results, which raises the costs considerably in addition to wasting fat tissue. Yoshimura et al. used four times the grafted fat volume for SVF isolation in their preclinical study on rodents [21], and, clinically, an approximately equal amount of grafted fat volume for SVF isolation [3] [21]. According to our results, intraoperative enrichment seems to be a waste of money, time and fat, and, therefore, fat collected with the WAL technique should be grafted as such. The pre-expansion of stem cells in laboratory conditions is the way to produce large amounts of stem cells, but it is another concept altogether and not comparable to intraoperative isolation.

Postlactational atrophy and a loose skin envelope create an empty scaffold that can be filled without tension. Cases 1 - 3 in the present study had a loose recipient site due to previous lactation or removal of implants. In a scarred recipient site (patient 4), both the compliance and vascularity of the tissue are poor, which diminishes the take rate. Furthermore, weight loss after fat transfer makes fat cells shrink, which partly explains the lower take rate in patient 4 . Weight gain increases the volume of fat cells and may result in a disproportionately good take rate. The expandability and vitality of the recipient site and the vitality of the graft may be the most important factors for the survival of technically correctly transplanted fat [11], and postharvest processing methods may play a minor role. Therefore, it is more important to choose the right method of harvesting than that of processing.

When harvesting large amounts of fat, fast and atraumatic harvesting is not only a question of comfort for both the patient and the surgeon but also of cell viability. The take rates of over $80 \%$ in the present study and $79 \%$ in our previous study reflect the high vitality of the non-enriched fat graft and thus the high predictability of the volume 
retention. As the mean take rate was identical in the first and second operations, the previous stem cell enrichment did not seem to enhance the take rate in the second operation.

The number of viable nucleated SVF (stromal vascular fraction) cells obtained by the Multi Station is $1.07 \times 10^{5}$ cells/g, which is less than what is achieved with the Cytori Celution $800 /$ CRS System $\left(2.41 \times 10^{5}\right.$ cells/g) but more than with two other commercial systems for isolating the stromal vascular fraction from fat tissue [25]. Out of these SVF cells, the amount of CD34+ adipose stem cells (ASC) or adipose-derived mesenchymal stem cells (adMSC) is much smaller (38.1\% in Multistation). WAL tissue is a valid source of adMSCs-the SVF from WAL tissue contains an average of $2.6 \times 10^{5} \mathrm{CD} 34+$ cells per $\mathrm{mL}$ of tissue [26]. Water-jet-assisted liposuction has recently been proven to yield fat grafts of better viability, fat graft retention and vascularisation as well as less apoptosis than conventional manual liposuction [27]. Stromal vascular fractions have been demonstrated to contain 42.25 percent of CD34 +/CD45- cells in samples collected by means of water-jet-assisted liposuction and 28.18 percent of CD34+/CD45cells after conventional manual liposuction [27]. The corresponding numbers of intact adipocytes in HE-stained images were $94.27 \%$ and $61.60 \%$, respectively. Manual liposuction is commonly utilized with cell-assisted lipotransfer. The poor viability and lesser amount of stem cells certainly benefit from stem cell enrichment. The difference in the quality of WAL fat grafts and manually aspirated fat explains why CAL has been shown to be beneficial in some studies but not in our studies with WAL fat. Enriching tissue that is already rich (in stem cells) is unnecessary. Only if very small amounts of WAL tissue can be used, such as in intra-articular injections for treating osteoarthrosis, further enrichment may be wise. Residual enzyme (collagenase) level observed with the Multi Station is 5.1-fold higher than that observed with the Celution System which seems to be lowest among the commercially available systems [25].

The high fluid content (32\%) in a WAL fat graft causes more postoperative swelling, which raises unrealistic expectations in patients. Whether it is possible to diminish swelling with the aid of filtering the graft with the new container that includes a filter and to further enhance WAL graft survival by avoiding cell-toxic local anaesthetics [28] remains to be investigated.

\section{Conclusion}

Intraoperative stem cell enrichment is not beneficial in correctly performed fat transplantation for breast augmentation if the fat has been harvested with water-jet-assisted liposuction (WAL). WAL can be utilized instead of CAL. However, the results of our study only apply to patients treated with water-assisted liposuction. If the graft has been collected manually, the viability of the graft is weaker, and stem cell enrichment may be necessary to achieve a good long-term result.

\section{Funding}

The MRI investigations were financed by Avohoidon Tutkimussäätiö, Helsinki, Finland. 


\section{Conflict of Interest Statement}

Human Med has covered travelling expenses for the invited speakers H.P. and C.H.

\section{Ethical Approval}

The research project was approved by the Ethics Committee of Tampere University Hospital, Finland (code R11014). All procedures performed in the study involving human participants were performed in accordance with the ethical standards of the institutional research committee and with the 1964 Declaration of Helsinki and its later amendments or comparable ethical standards.

\section{References}

[1] Aust, L., Devlin, B., Foster, S.J., Halvorsen, Y.D., Hicok, K., du Laney, T., et al. (2004) Yield of Human Adipose-Derived Adult Stem Cells from Liposuction Aspirates. Cytotherapy, 6, 7-14. http://dx.doi.org/10.1080/14653240310004539

[2] Eto, H., Suga, H., Matsumoto, D., Inoue, K., Aoi, N., Kato, H., et al. (2009) Characterization of Structure and cellular Components of Aspirated and Excised Adipose Tissue. Plastic and Reconstructive Surgery, 124, 1087-1097. http://dx.doi.org/10.1097/PRS.0b013e3181b5a3f1

[3] Yoshimura, K., Sato, K., Aoi, N., Kurita, M., Hirohi, T. and Harii, K. (2008) Cell-Assisted Lipotransfer for Cosmetic Breast Augmentation: Supportive Use of Adipose-Derived Stem/ Stromal Cells. Aesthetic Plastic Surgery, 32, 48-55, Discussion 56-47. http://dx.doi.org/10.1007/s00266-007-9019-4

[4] Tiryaki, T., Findikli, N. and Tiryaki, D. (2011) Staged Stem Cell-Enriched Tissue (SET) Injections for Soft Tissue Augmentation in Hostile Recipient Areas: A Preliminary Report. Aesthetic Plastic Surgery, 35, 965-971. http://dx.doi.org/10.1007/s00266-011-9716-x

[5] Kølle, S.F., Fischer-Nielsen, A., Mathiasen, A.B., Elberg, J.J., Oliveri, R.S., Glovinski, P.V., et al. (2013) Enrichment of Autologous Fat Grafts with EX-Vivo Expanded Adipose Tissue-Derived Stem Cells for Graft Survival: A Randomised Placebo-Controlled Trial. Lancet, 382, 1113-1120. http://dx.doi.org/10.1016/S0140-6736(13)61410-5

[6] Hyakusoku, H., Ogawa, R., Ono, S., Ishii, N. and Hirakawa, K. (2009) Complications after Autologous Fat Injection to the Breast. Plastic and Reconstructive Surgery, 123, 360-370, Discussion 371-362. http://dx.doi.org/10.1097/prs.0b013e31819347ba

[7] Peltoniemi, H.H., Salmi, A., Miettinen, S., Mannerström, B., Saariniemi, K., Mikkonen, R., et al. (2013) Stem Cell Enrichment Does Not Warrant a Higher Graft Survival in Lipofilling of the Breast: A Prospective Comparative Study. Journal of Plastic, Reconstructive \& Aesthetic Surgery, 66, 1494-1503. http://dx.doi.org/10.1016/j.bjps.2013.06.002

[8] Del Vecchio, D.A. and Bucky, L.P. (2011) Breast Augmentation Using Pre-Expansion and Autologous Fat Transplantation: A Clinical Radiographic Study. Plastic and Reconstructive Surgery, 27, 2441-2450. http://dx.doi.org/10.1097/PRS.0b013e3182050a64

[9] Herold, C., Knobloch, K., Grimme, M. and Vogt, P.M. (2010) Does the Injection Plane Matter in Autologous Fat Transplantation? Aesthetic Plastic Surgery, 34, 678-679. http://dx.doi.org/10.1007/s00266-010-9490-1

[10] Herold, C., Ueberreiter, K., Cromme, F., Busche, M.N. and Vogt, P.M. (2010) The Use of Mamma MRI Volumetry to Evaluate the Rate of Fat Survival after Autologous Lipotransfer. Handchirurgie, Mikrochirurgie, Plastische Chirurgie, 42, 129-134. http://dx.doi.org/10.1055/s-0029-1243204 
[11] Khouri, R.K., Eisenmann-Klein, M., Cardoso, E., Cooley, B.C., Kacher, D., Gombos, E., et al. (2012) Brava(R) and Autologous Fat Transfer Is a Safe and Effective Breast Augmentation Alternative: Results of a Six-Year, Eighty-One Patients Prospective Multicenter Study. Plastic and Reconstructive Surgery, 129, 1173-1187. http://dx.doi.org/10.1097/PRS.0b013e31824a2db6

[12] Ueberreiter, K. (2010) BEAULI ${ }^{\mathrm{TM}}$ - eine neue Methode zur einfachen und zuverlässigen Fettzell-Transplantation. Handchirurgie, Mikrochirurgie, Plastische Chirurgie, 42, 379-385. http://dx.doi.org/10.1055/s-0030-1267913

[13] Herold, C., Ueberreiter, K., Busche, M.N. and Vogt, P.M. (2013) Autologous Fat Transplantation: Volumetric Tools for Estimation of volume survival. A systematic Review. Aesthetic Plastic Surgery, 37, 380-387. http://dx.doi.org/10.1007/s00266-012-0046-4

[14] Herold, C., Reichelt, A., Stieglitz, L.H., Dettmer, S., Knobloch, K., Lotz, J., et al. (2010) MRI-Based Breast Volumetry-Evaluation of Three Different Software Solutions. Journal of Digital Imaging, 23, 603-610. http://dx.doi.org/10.1007/s10278-009-9264-y

[15] Herold, C., Knobloch, K., Rennekampff, H.O., Ueberreiter, K. and Vogt, P.M. (2010) Magnetic Resonance Imaging-Based Progress Control after Autologous Fat Transplantation. Plastic and Reconstructive Surgery, 126, 260e-261e. http://dx.doi.org/10.1097/PRS.0b013e3181ef938c

[16] Zhu, M., Zhou, Z., Chen, Y., Schreiber, R., Ransom, J.T., Fraser, J.K., et al. (2010) Supplementation of Fat Grafts with Adipose-Derived Regenerative Cells Improves Long-Term Graft Retention. Annals of Plastic Surgery, 64, 222-228. http://dx.doi.org/10.1097/SAP.0b013e31819ae05c

[17] Lu, F., Li, J., Gao, J., Ogawa, R., Ou, C., Yang, B., et al. (2009) Improvement of the Survival of Human Autologous Fat Transplantation by Using VEGF-Transfected Adipose-Derived Stem Cells. Plastic and Reconstructive Surgery, 124, 1437-1446. http://dx.doi.org/10.1097/PRS.0b013e3181babbb6

[18] Coleman, S. (2009) Augmentation of the Breast with Structural Fat. In: Coleman, S.R. and Mazzola, R.F., Eds., Fat Injection. From Filling to Regeneration, Quality Medical Publishing Inc., St. Louis.

[19] Coleman, S.R. and Saboeiro, A.P. (2007) Fat Grafting to the Breast Revisited: Safety and Efficacy. Plastic and Reconstructive Surgery, 119, 775-785, Discussion 786-777.

[20] Matsumoto, D., Sato, K., Gonda, K., Takaki, Y., Shigeura, T., Sato, T., et al. (2006) Cell-Assisted Lipotransfer: Supportive Use of Human Adipose-Derived Cells for Soft Tissue Augmentation with Lipoinjection. Tissue Engineering, 12, 3375-3382. http://dx.doi.org/10.1089/ten.2006.12.3375

[21] Yoshimura, K., Asano, Y., Aoi, N., Kurita, M., Oshima, Y., Sato, K., et al. (2009) Progenitor-Enriched Adipose Tissue Transplantation as Rescue for Breast Implant Complications. The Breast Journal, 16, 169-175. http://dx.doi.org/10.1111/j.1524-4741.2009.00873.x

[22] Rigotti, G., Marchi, A., Micciolo, R. and Baroni, G. (2012) Autologous Fat Grafting in Breast Cancer Patients. Breast, 21, 690. http://dx.doi.org/10.1016/j.breast.2012.06.002

[23] Condé-Green, A., de Amorim, N.F. and Pitanguy, I. (2010) Influence of Decantation, Washing and Centrifugation on Adipocyte and Mesenchymal Stem Cell Content of Aspirated Adipose Tissue: A Comparative Study. Journal of Plastic, Reconstructive \& Aesthetic Surgery, 63, 1375-1381. http://dx.doi.org/10.1016/j.bjps.2009.07.018

[24] Eto, H., Kato, H., Suga, H., Aoi, N., Doi, K., Kuno, S., et al. (2012) The Fate of Adipocytes After Nonvascularized Fat Grafting: Evidence of Early Death and Replacement of Adipocytes. Plastic and Reconstructive Surgery, 129, 1081-1092. 
http://dx.doi.org/10.1097/PRS.0b013e31824a2b19

[25] Aronowitz, J. and Ellenhorn, J. (2013) Adipose Stromal Vascular Fraction Isolation: A Head-to-Head Comparison of Four Commercial Cell Separation Systems. Plastic and Reconstructive Surgery, 132, 932e-939e. http://dx.doi.org/10.1097/PRS.0b013e3182a80652

[26] Meyer, J., Salamon, A., Herzmann, N., Adam, S., Kleine, H.D., Matthiesen, I., et al. (2015) Isolation and Differentation Potential of Human Mesenchymal Stem Cells from Adipose Tissue Harvested by Water Jet-Assisted Liposuction. Aesthetic Surgery Journal, 35, 10301039. http://dx.doi.org/10.1093/asj/sjv075

[27] Yin, S., Luan, J., Fu, S., Wang, Q. and Zhuang, Q. (2015) Does Water-Jet Force Make a Difference in Fat Grafting? In vitro and in Vivo Evidence of Improved Lipoaspirate Viability and Fat Graft Survival. Plastic and Reconstructive Surgery, 135, 127-138. http://dx.doi.org/10.1097/PRS.0000000000000780

[28] Keck, M., Zeyda, M., Gollinger, K., Burjak, S., Kamolz, L.P., Frey, M., et al. (2010) Local Anesthetics Have a Major Impact on Viability of Preadipocytes and Their Differentiation to Adipocytes. Plastic and Reconstructive Surgery, 126, 1500-1505.

http://dx.doi.org/10.1097/PRS.0b013e3181ef8beb

Submit or recommend next manuscript to SCIRP and we will provide best service for you:

Accepting pre-submission inquiries through Email, Facebook, LinkedIn, Twitter, etc.

A wide selection of journals (inclusive of 9 subjects, more than 200 journals)

Providing 24-hour high-quality service

User-friendly online submission system

Fair and swift peer-review system

Efficient typesetting and proofreading procedure

Display of the result of downloads and visits, as well as the number of cited articles

Maximum dissemination of your research work

Submit your manuscript at: http://papersubmission.scirp.org/

Or contact ss@scirp.org 